\title{
CONDITIONS FOR PARTIAL AND COMPLETE CRYSTALLIZATION SUPPRESSION UPON QUENCHING FROM LIQUID STATE
}

\author{
O.B. Lysenko ${ }^{1 *}$, T.V. Kalinina ${ }^{1}$, I.V. Zagorulko ${ }^{2}$ \\ ${ }^{1}$ Dnipro State Technical University, Kamianske, Ukraine \\ ${ }^{2}$ G. V. Kurdyumov Institute for Metal Physics of the N.A.S. of Ukraine, Kyiv, Ukraine \\ *e-mail: ablysenko@ukr.net
}

For bulk-amorphizing alloys $\mathrm{Mg}_{65} \mathrm{Cu}_{25} \mathrm{Y}_{10}$ and $\mathrm{Zr}_{41,2} \mathrm{Ti}_{13,8} \mathrm{Cu}_{12,5} \mathrm{Ni}_{10} \mathrm{Be}_{22,5}$, the thickness and cooling rate of melt layers is calculated, which ensure the formation of $\mathrm{X}$-ray amorphous structures typical for metallic glasses $\left(l_{C}, v_{C}\right)$, and truly amorphous states without inclusions of «frozen-in crystallization centers» $\left(l_{C}^{*}, v_{C}^{*}\right)$. Correlation of the calculated values $l_{C}, v_{C}$ with the known experimental estimates is achieved. It is shown that both studied alloys demonstrate a predisposition to complete suppression of crystallization processes at physically correct values of the parameters $l_{C}^{*}$ and $v_{C}^{*}\left(10 \mu \mathrm{m} ; 1,3 \cdot 10^{7} \mathrm{~K} / \mathrm{s}\right.$ and $550 \mu \mathrm{m} ; 2,7 \cdot 10^{3} \mathrm{~K} / \mathrm{s}$ for alloys based on $\mathrm{Mg}$ and $\mathrm{Zr}$, respectively). It is concluded that the most significant factors controlling the tendency of materials to noncrystalline solidification are the decrease in the frequency of non-stationary nucleation with the increase in the rate of QLS, as well as relatively low $<10^{18}$ $\mathrm{m}^{-3} \mathrm{~s}^{-1}$ ) maximum values of the rate of stationary crystallization centers formation.

Keywords: quenching of metal melts, thermal regimes, crystallization kinetics, metallic glasses, truly amorphous structures, factors of non-crystalline solidification.

Received 10.06.2021; Received in revised form 22.07.2021; Accepted 15.08.2021

\section{Introduction}

In the history of metal physics, Professor of Dnepropetrovsk State University (now Oles Honchar Dnipro National University) Ivan Stepanovich Miroshnichenko takes the honorable place of the founder of the scientific and technological direction, called quenching from a liquid state (QLS). A deep understanding of the regularities of the metal alloys structure formation under the influence of various factors, including the cooling rate, in combination with the talent of an experimental physicist allowed him not only to predict the effectiveness of a fundamentally new type of heat treatment as a way of fixing morphological changes in the microstructure, the formation of abnormally supersaturated solid solutions, metastable crystalline and amorphous phases, but also to obtain experimental confirmation of the listed structural effects. The most important results of scientific research by I.S. Miroshnichenko are summarized in the monograph [1], which for many years has been a source of basic knowledge for physicists and materials scientists interested in the problem of QLS.

In recent decades, the scientific undertakings of I.S. Miroshnichenko are developing and improving in the works of metal physicists of a new formation, prepared by his students at universities and academic institutes of Dnipro, Kyiv, Donetsk, Zaporizhzhia, Kamianske and other cities of Ukraine. In particular, at the Department of Condensed Matter Physics of Dnipro State Technical University, there is a scientific school focused on complex studies of the relationships of the dynamic mode of QLS with the kinetics of nonequilibrium crystallization of metal melts, as well as on the development of new amorphous and nanocrystalline alloys, methods for their preparation and expansion of the scope of technical use.

This paper presents the results of research by a team of authors belonging to the above scientific school. The work was carried out in the development of thinking of I.S. Miroshnichenko [2] concerning to the nature of the amorphous state in rapidly quenched materials. Its main goal was a comparative computational analysis of the critical cooling rates $v_{C}$ and $v_{C}^{*}$, which ensure the formation of conditionally amorphous structures, typical for metallic glasses (MG), and truly amorphous states (TAS), devoid of inclusions of «quenched 
(or frozen-in) nuclei». The objects of research were multicomponent alloys based on magnesium $\left(\mathrm{Mg}_{65} \mathrm{Cu}_{25} \mathrm{Y}_{10}\right)$ and zirconium $\left(\mathrm{Zr}_{41,2} \mathrm{Ti}_{13,8} \mathrm{Cu}_{13,5} \mathrm{Ni}_{10} \mathrm{Be}_{22,5}\right)$, which demonstrate a tendency to bulk amorphization at casting into a metal mold $[3,4]$. The choice of the given alloys is dictated by the availability of literature data on the temperature dependences of the parameters which settings the crystallization kinetics, as well as experimental estimates of the critical cooling rates $v_{C}^{\exp }$ sufficient for the formation of the MG structure.

\section{Principles of Modeling Crystallization Processes in Conditions of QLS}

To achieve this purpose, we used the method of coordinated numerical solution of differential equations of thermal conductivity for the melt and heat sink with the equation of mass crystallization kinetics obtained within the approximation of effective rates of nucleation and crystals growth [5]. The advantage of the used approximation is the possibility of complex processes analyzing, for example, competitive crystallization with the participation of equilibrium and metastable phases $[6,7]$ or solidification of the laser reflow zone, which is carried out using two alternative crystallization mechanisms [8]. In addition, the approach [5] facilitates the procedure for calculating the microstructural parameters of the products of the QLS $[9,10]$.

In part of the physical assumptions of the model for melt layers with a thickness of $l \geq 1 \mathrm{~mm}$, the scheme of casting into a metal mold with walls of finite thickness was used [11]. Studies of thinner $(l<1 \mathrm{~mm})$ layers were based on a scheme for removing heat into a semi-infinite copper substrate [9], which corresponds to the cooling principle in the most common method of melt spinning.

Taking into account the results of electron microscopic studies of the size, morphology and nature of the distribution of crystalline phase inclusions in the structure of metallic glasses $[12,13]$, it was considered that they are the result of the action of mechanisms of homogeneous nucleation and further isotropic growth of spherical crystallization centers. When creating a combined model of partial and complete crystallization suppression, we proceeded from the fact that with an increase in the cooling rate $v$ conditions are consistently created, under which growth processes become impossible ( $v=v_{C} ; x_{e} \approx 10^{-2}$, where $x_{e}$ is the resulting crystallized volume fraction), and then the nucleation of crystals $\left(v=v_{C}^{*} ; N_{e}^{V}<1\right.$, where $N_{e}^{V}$ - the total number of crystallization centers arising in the investigated volume $V$ during the cooling of the melt from the melting point $T_{m}$ to the glassy solidification temperature $T_{g}$ ). In connection with the above, two series of calculations were performed.

In the calculations of the first series, the critical thickness $l_{C}$ of the melt layers (or the half-thickness of chill castings) and the corresponding values of the cooling rate $v_{C}$ at which the volume fraction of crystalline phase inclusions is $x_{e} \approx 10^{-2}$ and, therefore, cannot be detected by X-ray phase analysis, were determined. The proportion of the volume $x$ that underwent crystallization at a given time was calculated using the integral equation [5]:

$$
x(t)=\frac{3}{4} \pi \int_{t_{m}}^{t}\left(1-x\left(t^{\prime}\right)\right) I\left(t^{\prime}\right)\left[R_{C}\left(t^{\prime}\right)+\int_{t^{\prime}}^{t}\left(1-x\left(t^{\prime \prime}\right)\right) u\left(t^{\prime \prime}\right) d t^{\prime \prime}\right]^{3} d t^{\prime} .
$$

where $I$ is the nucleation frequency; $R_{C}$ is the radius of the crystal nucleus of critical size; $u$ is the crystal growth rate; $t_{m}$ is the time the melt reaches the melting temperature $T_{m}$; 
$t, t^{\prime}, t^{\prime \prime}$ - current moments of time $\left(t_{m} \leq t^{\prime} \leq t^{\prime \prime} \leq t \leq t_{e}, t_{e}\right.$ - the moment of completion of the transformation $\left(x_{e} \approx 0,99\right.$ or $\left.T_{e}=T_{g}\right)$ ).

The parameters $I, R_{C}, u$, included in Eq. (1) were determined by the formulas of the classical theory of crystallization $[14,15]$ for the mechanisms of homogeneous nucleation and normal growth of crystals. All the details of the calculations of the critical parameters $l_{C}, v_{C}$ reflecting the conditions for the formation of the metallic glasses structure are given in $[9,11]$.

The calculation analysis of the conditions for complete crystallization suppression was carried out on the basis that amorphous structures devoid of «quenching nuclei»can be obtained only in layers with a thickness $l<l_{C}$, the cooling rate of which exceeds the critical level $v_{C}$. Therefore, in the second block of calculations, for different values of $l<l_{C}$, the number of crystallization centers $N_{e}^{V}$ that are formed during the passage of the temperature interval $T_{m}-T_{g}$ in a given volume $V=S \cdot l$ was determined, where $S=10^{-4} \mathrm{~m}^{2}$ is the surface area of the samples used in structural studies. Calculations were carried out according to the ratio:

$$
N_{e}^{V}=S \cdot l \int_{T_{g}}^{T_{m}}[v(T)]^{-1} I(T) d T .
$$

The temperature dependences of the nucleation frequency $I(T)$ were calculated by the method [16] taking into account the nonstationary character of the size distribution of heterophase fluctuations under conditions of rapid cooling of the melt:

$$
\begin{gathered}
I(T)=I_{0}(T) \exp (-\tau / t), \\
I_{0}(T)=N_{V} D(T) \exp \left\{-16 \pi V_{m}^{2} \sigma^{3} /\left[3 \Delta G_{m}^{2}(T) \cdot k_{b} T\right]\right\} \cdot a_{0}^{-2}, \\
\tau=\pi V_{m}^{2} \sigma^{2} /\left[D(T) \Delta G_{m}^{2}(T)\right], \\
t=\int_{T}^{T_{m}}[v(T)]^{-1} d T .
\end{gathered}
$$

where $I_{0}$ - is the stationary nucleation frequency; $\tau$ - is the time to establish a stationary size distribution of subcritical nuclei; $t$ - is the cooling time of the melt from $T_{m}$ to $T ; N_{V}-$ is the number of atoms per unit volume; $D$ - is the diffusion coefficient of atoms at the melt-crystal interface; $a_{0}$ - is the thickness of the interface (atomic diameter); $V_{m}-$ is the molar volume; $\sigma$ - is the specific free energy of the crystal surface; $\Delta G_{m}$ - is the difference between the molar free energies of the liquid and crystalline phases; $k_{b}-$ Boltzmann constant.

The $D$ value was expressed in terms of the dynamic viscosity of the melt $\eta$ using the Stokes-Einstein relation:

$$
D(T)=k_{b} T /\left[3 \pi \cdot a_{0} \cdot \eta(T)\right] .
$$

Taking into account relations (3) - (7), equation (2) was transformed to the form:

$$
N_{e}^{V}=S \cdot l \int_{T_{g}}^{T_{m}}\left[k_{1} T /(\eta(T) v(T))\right] \cdot \exp \left[-k_{2} /\left(T \Delta G_{m}^{2}(T)\right)\right] \cdot \exp \left[-k_{3} \eta(T) /\left(T \Delta G_{m}^{2}(T) \int_{T}^{T_{m}}(v(T))^{-1} d T\right] d T .\right.
$$


where

$$
\begin{gathered}
k_{1}=N_{V} k_{b} /\left(3 \pi \cdot a_{0}^{3}\right), \\
k_{2}=16 \pi V_{m}^{2} \sigma^{3} /\left(3 k_{b}\right), \\
k_{3}=3 \pi^{2} a_{0} \cdot V_{m}^{2} \sigma^{2} / k_{b} .
\end{gathered}
$$

As a criterion for the tendency of materials to suppress the nucleation process, we considered the critical thickness of the layers $l_{C}^{*}$, which ensures the fulfillment of the inequality $N_{e}^{V}<1$. The corresponding value of the critical cooling rate $v_{C}^{*}$ was determined by joint analysis of the dependences $v(T)$ and $I(T)$, giving to the parameter $v_{C}^{*}$ the values of the function $v(T)$ at the temperature of the maximum nucleation frequency.

The magnitude of the thermodynamic stimulus of crystallization $\Delta G_{m}(T)$ for the $\mathrm{Mg}$ alloy was calculated by the ratio:

$$
\Delta G_{m}(T)=\Delta H_{m} \cdot \Delta T / T_{m}+\int_{T_{m}}^{T} \Delta C_{p}\left(T^{\prime}\right) d T^{\prime}-T^{\prime} \int_{T_{m}}^{T}\left(\Delta C_{p}\left(T^{\prime}\right) / T^{\prime}\right) d T^{\prime} .
$$

where $\Delta C_{P}$ is the difference in the specific heat capacities of the liquid and crystalline phases.

In this case, we used the experimental values $\Delta H_{m}=8,65 \cdot 10^{3} \mathrm{~J} / \mathrm{mol}, T_{m}=780 \mathrm{~K}$ and the temperature dependence $\Delta C_{P}(T)$ from [3]:

$$
\Delta C_{p}(T)=17,52 \cdot 10^{-3}+1,8 \cdot 10^{6} \cdot T^{-2}-1,02 \cdot 10^{-5} \cdot T^{2} .
$$

For the Zr-based alloy, the $\Delta G_{m}(T)$ values were determined using the empirical relation given in [4]:

$$
\Delta G_{m}(T)=1,58 \cdot 10^{-4}-7,97 \cdot T-4,09 \cdot 10^{6} \cdot T^{-1}-7,76 \cdot 10^{-3} \cdot T^{2}+3,46 \cdot 10^{-6} \cdot T^{3}
$$

The values of the viscosity of supercooled melts for the compositions $\mathrm{Mg}_{65} \mathrm{Cu}_{25} \mathrm{Y}_{10}$ and $\mathrm{Zr}_{41,2} \mathrm{Ti}_{13,8} \mathrm{Cu}_{13,5} \mathrm{Ni}_{10} \mathrm{Be}_{22,5}$ were determined using the experimental dependences $\eta(T)$ from [3] and [17], respectively.

The specific free energy of the interface between the crystalline phase and the melt $\sigma$ was considered independent of temperature and was estimated according to the procedure described in [18].

\section{Conditions for the formation of metallic glasses}

In accordance with the supplied tasks, in the first block of model calculations for the investigated alloys, the critical parameters $l_{C}, v_{C}$, which ensure the fulfillment of the condition $x_{e} \approx 10^{-2}$, were determined. The primary results of the calculations were obtained in the form of graphs of the time change of temperature and the converted volume fraction for melt layers of different thicknesses. As an example, Fig. 1 shows the dependences $T(t)$ and $x(t)$ for the $\mathrm{Mg}_{65} \mathrm{Cu}_{25} \mathrm{Y}_{10}$ alloy.

A cooperative analysis of the presented temperature and kinetic curves allows us to conclude that crystallization in relatively thin layers $\left(l=3 \cdot 10^{-3} \mathrm{~m}\right)$ does not significantly affect the course of the dependence $T(t)$, which demonstrates continuous cooling of the 
melt. This means that the value of the released latent heat of transformation is negligible in comparison with the heat flux removed from the melt to the quenching block. The end result of such a thermal regime is the glassy solidification of the supercooled melt at temperature $T_{g}$ with the formation of a metallic glass structure consisting of an amorphous matrix and inclusions of "quenched nuclei". For the example under consideration, the volume fraction of crystallization centers does not exceed $\approx 10^{-2}$, and their number per unit volume and average dimensions are $2.7 \cdot 10^{13} \mathrm{~m}^{-3}$ and $6.2 \cdot 10^{-7} \mathrm{~m}$, respectively.

The dependences $T(t)$ and $x(t)$ for Mg-alloy layers with a thickness of $1=1.2 \cdot 10^{-2}$ $\mathrm{m}$ also have a fundamentally different character (dashed curves in Fig. 1). As can be seen, at different stages of the process, the solidification of the melt occurs under different thermal conditions. At the initial stage, the ratio of the heat flux released to the substrate is added in favor of the latter, whereupon the layer temperature decreases. However, when the volume fraction of the crystalline phase $x \approx 10^{-2}$ is reached, the flow of the latent heat of transformation becomes dominant, which leads to the appearance of a recalescent section in the dependence $T(t)$.

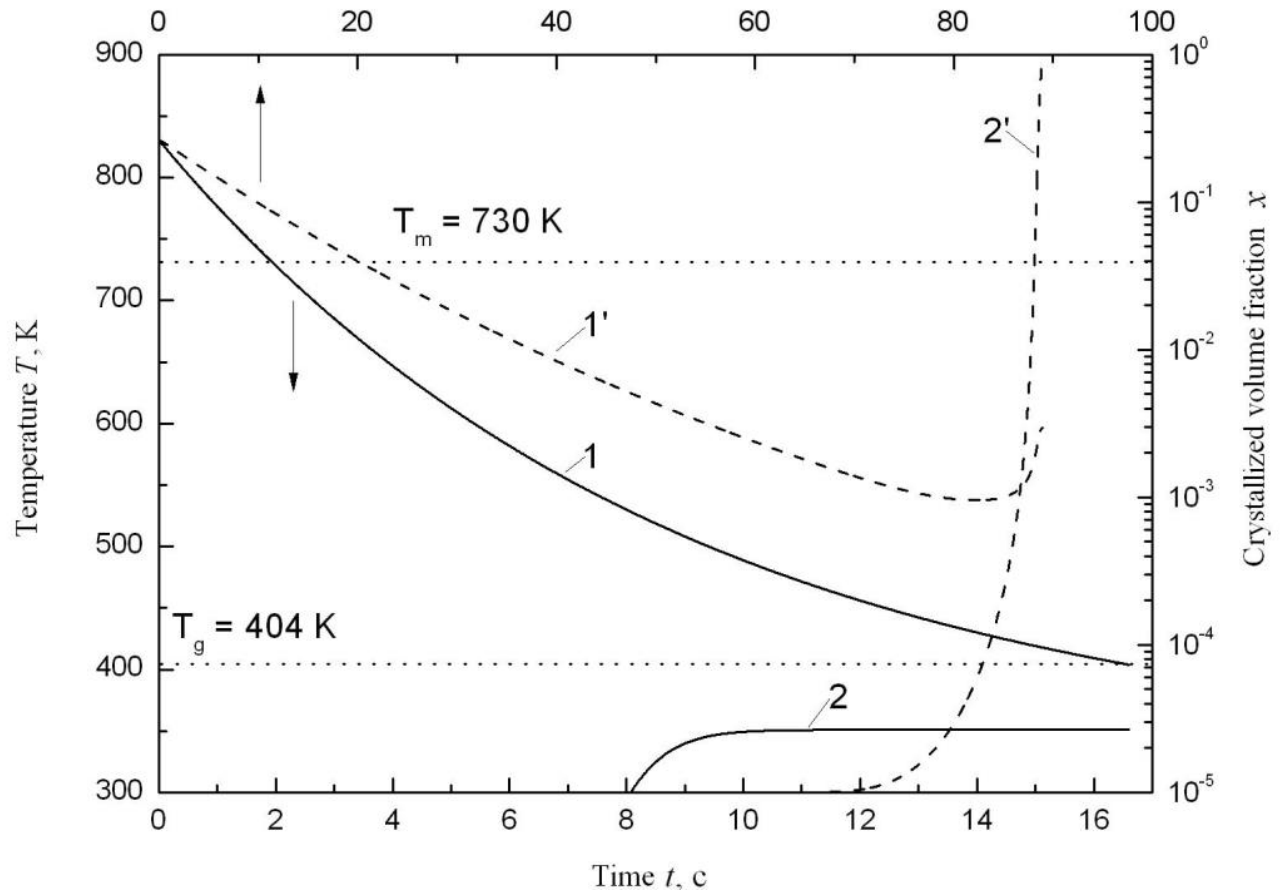

Fig. 1. Calculated dependences $T(t)$ and $x(t)$ for $\mathrm{Mg}_{65} \mathrm{Cu}_{25} \mathrm{Y}_{10}$ alloy solidifying layers with a thickness of $l=3 \cdot 10^{-3} \mathrm{~m}(1,2)$ and $l=1.2 \cdot 10^{-2} \mathrm{~m}\left(1^{\prime}, 2^{\prime}\right)$

In turn, the qualitative change in the temperature regime of the partially crystallized layer from cooling to heating is accompanied by an abrupt decrease in the nucleation frequency to such low values at which the formation of new crystallization centers ceases. In this case, the crystal growth rate decreases insignificantly. As a result of the observed changes in the kinetic parameters of $I, u$ at the final stage of solidification, crystallization occurs exclusively through the growth of previously formed centers, which causes a roughening of the microstructure. Under the influence of the considered thermal regime, completely crystallized structures $\left(x_{e} \approx 0,99\right)$ with an average crystal size $\bar{R}_{e} \approx 5 \cdot 10^{-5} \mathrm{~m}$ are formed. Similar features of thermal regimes and crystallization kinetics were also 
revealed by calculations for conventionally "thin" and "thick" layers of a zirconiumbased alloy.

In order to determine the critical values of the thickness $l_{C}$ of the melt layers and the corresponding cooling rate $v_{C}$ at which structures of metallic glasses are formed in the alloys under study, the final value of the crystallized volume fraction $x_{e}$ was calculated for layers of different thicknesses, and then the dependences $x_{e}(l)$ shown in Fig. 2 were plotted.

In the analyzed figure, the dotted line shows a value $x_{e}=10^{-2}$ that is commensurate with the sensitivity of the X-ray phase analysis and, therefore, is not detected in the X-ray diffraction patterns. The values of the critical parameter $l_{C}$ were determined from the points of intersection of the dependencies $x_{e}(l)$ with the dashed line. The corresponding critical cooling rates $v_{C}$ were calculated using the relations $\lg v=f(\lg l)$ proposed in [19] for three intervals of $l$ values, each of which belongs to a certain group of QLS methods: $l<20 \mu \mathrm{m}$ - the «shot» method; $l<(20-100)$ microns - methods of rapid cooling of melts on moving heat-conducting substrates; $l>100 \mu \mathrm{m}$ - mold casting methods.

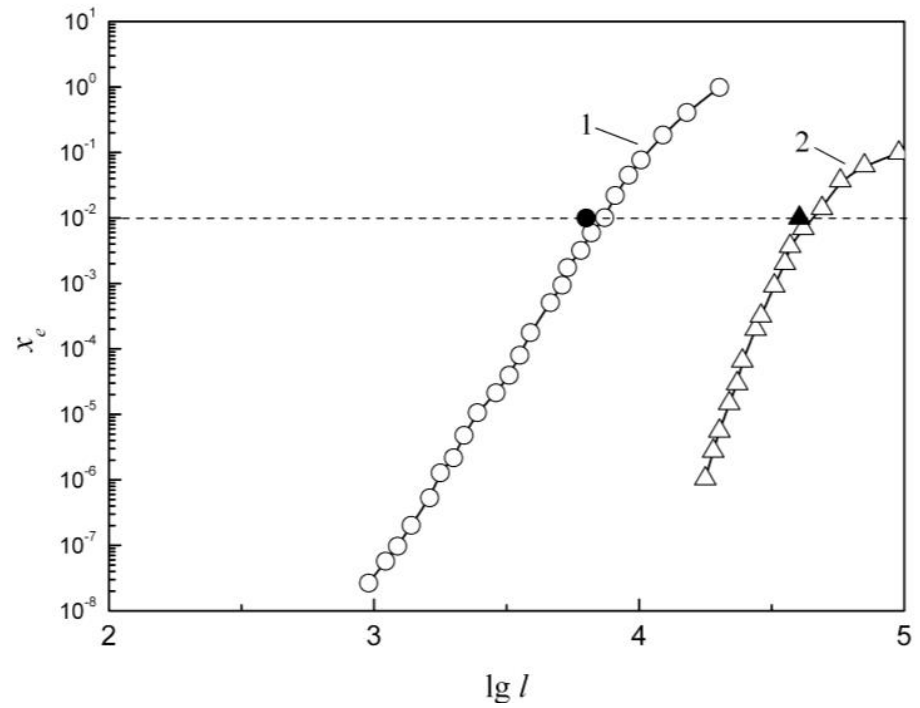

Fig. 2. Dependences of the final crystallized volume fraction $x_{e}$ on the layer thickness of the studied alloys: 1 - $\mathrm{Mg}_{65} \mathrm{Cu}_{25} \mathrm{Y}_{10}, 2-\mathrm{Zr}_{41.2} \mathrm{Ti}_{13.8} \mathrm{Cu}_{12.5} \mathrm{Ni}_{10} \mathrm{Be}_{22.5}$. The dark symbols mark the experimental estimates of the parameter $l_{C}$.

The found values of the parameters $l_{C}, v_{C}$ agree with the known experimental estimates of the critical thickness and cooling rate of the layers of the $\operatorname{Mg}_{65} \mathrm{Cu}_{25} \mathrm{Y}_{10}$ and $\mathrm{Zr}_{41,2} \mathrm{Ti}_{13,8} \mathrm{Cu}_{13,5} \mathrm{Ni}_{10} \mathrm{Be}_{22,5}$ melts, which ensure the formation of the metallic glasses structure (Fig. 2, Table 1). The achieved correlation between the calculated and experimental data indicates the adequacy of the used mathematical model and the correctness of the results obtained with its help.

\section{Conditions of for truly amorphous structures fixation}

In the second block of calculations, the fundamental possibility and conditions of obtaining single-phase amorphous structures in the alloys under study were studied. As noted above, the quantitative criterion for the formation of TAS is the inequality $N_{e}^{V}<1$, 
which means that during the cooling of the melt from $T_{m}$ to $T_{g}$, not a single crystallization center is formed in the volume of rapidly quenched samples. To solve this problem, we calculated the cooling curves $T(t)$ and graphs of the change with time in the number of crystalline nuclei arising in a given volume $N^{V}(t)$.

According to obtained calculated data, which are graphically presented in Fig. 3 for Zr-alloy layers of different thicknesses $l<l_{C}$, the formation of QLS products is carried out under conditions of a continuous decrease in temperature. It was found that the processes of crystal nucleation begin at deep supercooling of the melt $\left(\Delta T_{r} \approx 0,2\right)$ and practically ends at temperatures $T_{e n}$ close to $T_{g}\left(T_{e n}=T_{g}+(40-90) K\right)$. Comparative analysis of the final values of the number of crystallization centers $N_{e}^{V}$ formed in the alloys under study shows that, firstly, as $l$ decreases, the value $N_{e}^{V}$ significantly decreases, and, secondly, for the $\mathrm{Zr}$-based alloy at the identical values of $l$ it is considerably less than for Mg-alloy. The latter result indicates a higher predisposition of the $\mathrm{Zr}$-alloy to complete suppression of crystallization processes with fixation of a truly amorphous state.

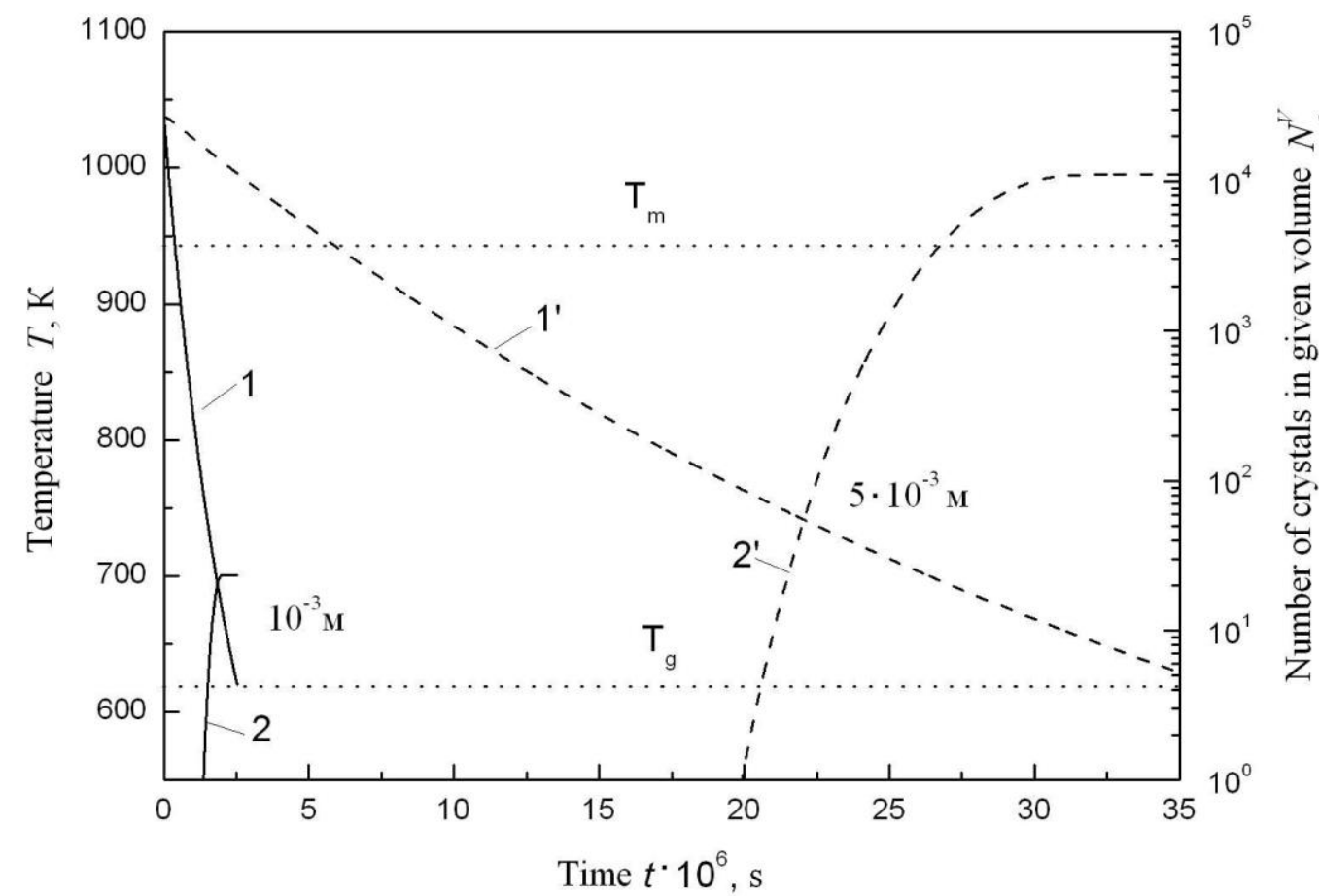

Fig. 3. Calculated dependences $T(t)\left(1,1^{\prime}\right)$ and $N^{V}(t)\left(2,2^{\prime}\right)$ for layers of $\mathrm{Zr}_{41.2} \mathrm{Ti}_{13.8} \mathrm{Cu}_{12.5} \mathrm{Ni}_{10} \mathrm{Be}_{22.5}$ alloy with thickness $l<l_{C}: 10^{-3} \mathrm{~m}(1,2)$ and $5 \cdot 10^{-3} \mathrm{~m}\left(1^{\prime}, 2^{\prime}\right)$

In order to verify this conclusion, the dependences $N_{e}^{V}(l)$ were calculated by varying the thickness of the melt layers in the range from $l_{C}\left(x_{e} \approx 10^{-2}\right)$ to $l_{C}^{*}\left(N_{e}^{V} \approx 1\right)$. The corresponding results are summarized in Fig. 4.

The dashed straight line in the lower part of the figure corresponds to the value $N_{e}^{V}=1$, and the points of its intersection with the graphs $N_{e}^{V}(l)$ correspond to the values of the critical thickness of the melt layers $l_{C}^{*}$ at which the action of the crystal nucleation mechanism is suppressed. It can be seen that both studied alloys exhibit a tendency to complete suppression of crystallization at the values of $l_{C}^{*}=10 \mu \mathrm{m}$ for the Mg-based alloy 
and $l_{C}^{*}=550 \mu \mathrm{m}$ for the $\mathrm{Zr}$-alloy. Such thicknesses of the melt layers correspond to the values of the critical cooling rates $v_{C}^{*}$ equal to $1,3 \cdot 10^{7} \mathrm{~K} / \mathrm{s}$ and $2,7 \cdot 10^{3} \mathrm{~K} / \mathrm{s}$ (Table 1 ).

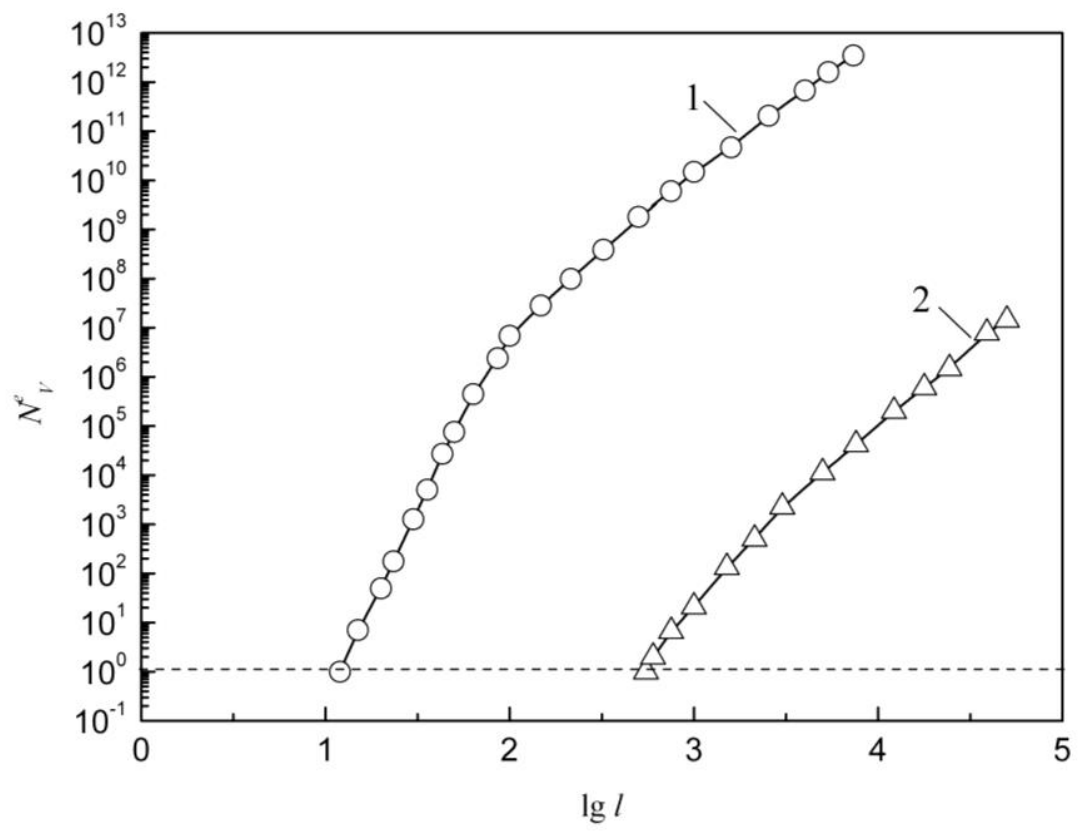

Fig. 4. Dependences of number of crystals $N_{e}^{V}$ which are formed in given volume during cooling from $T_{m}$ to $T_{g}$, on layer thickness $l<l_{c}$, for alloys based on $\mathrm{Mg}(1)$ and $\mathrm{Zr}(2)$

Critical values of parameters which provides the formation of conditionally and truly amorphous structures in QLS-products

\begin{tabular}{|c|c|c|c|c|c|c|}
\hline \multirow{2}{*}{ Alloy } & \multicolumn{5}{|c|}{ Thickness $l(\mu \mathrm{m})$ and cooling rate $v(\mathrm{~K} / \mathrm{s})$ of melt layers } \\
\cline { 2 - 7 } & $l_{C}$ & $l_{c}^{\exp }$ & $v_{C}$ & $v_{C}^{\exp }$ & $l_{C}^{*}$ & $v_{C}^{*}$ \\
\hline $\mathrm{Mg}_{65} \mathrm{Cu}_{25} \mathrm{Y}_{10}$ & $7,4 \cdot 10^{3}$ & $\begin{array}{c}4 \cdot 10^{3}[20] \\
7 \cdot 10^{3}[3]\end{array}$ & 34 & $50[20]$ & 10 & $1,3 \cdot 10^{7}$ \\
\hline $\mathrm{Zr}_{41,2} \mathrm{Ti}_{13,8} \mathrm{Cu}_{13,5} \mathrm{Ni}_{10} \mathrm{Be}_{22,5}$ & $50 \cdot 10^{3}$ & $50 \cdot 10^{3}[20]$ & 1,3 & $\begin{array}{c}1,0 \\
{[20]} \\
1,8 \\
{[21]}\end{array}$ & 550 & $2,7 \cdot 10^{3}$ \\
\hline
\end{tabular}

The obtained results of the computational analysis allow us to conclude that the $\mathrm{Mg}_{65} \mathrm{Cu}_{25} \mathrm{Y}_{10}$ alloy can be transformed into an amorphous state without inclusions of «frozen-in crystallization centers» by the method of melt spinning, and the $\mathrm{Zr}_{41,2} \mathrm{Ti}_{13,8} \mathrm{Cu}_{12,5} \mathrm{Ni}_{10} \mathrm{Be}_{22,5}$ alloy - by injection molding into a metal mold.

\section{Analysis of the factors controlling the tendency of materials to complete suppressing of crystallization processes}

In accordance with the condition $N_{e}^{V}<1$, the tendency of materials to form truly amorphous structures is determined by the nucleation kinetics, which indicates the need for a detailed analysis of the influence of compositional and technological factors on the frequency of formation of crystallization centers in a supercooled melt. For this purpose, 
by using Eqs. (3) - (6), we calculated the dependences of the frequencies of stationary $I_{0}$ and nonstationary $I$ crystal nucleation on the reduced supercooling of the melts $\Delta T_{r}$ (Fig. 5). The dependences $I\left(\Delta T_{r}\right)$ were calculated for different cooling rates $v<v_{C}$.

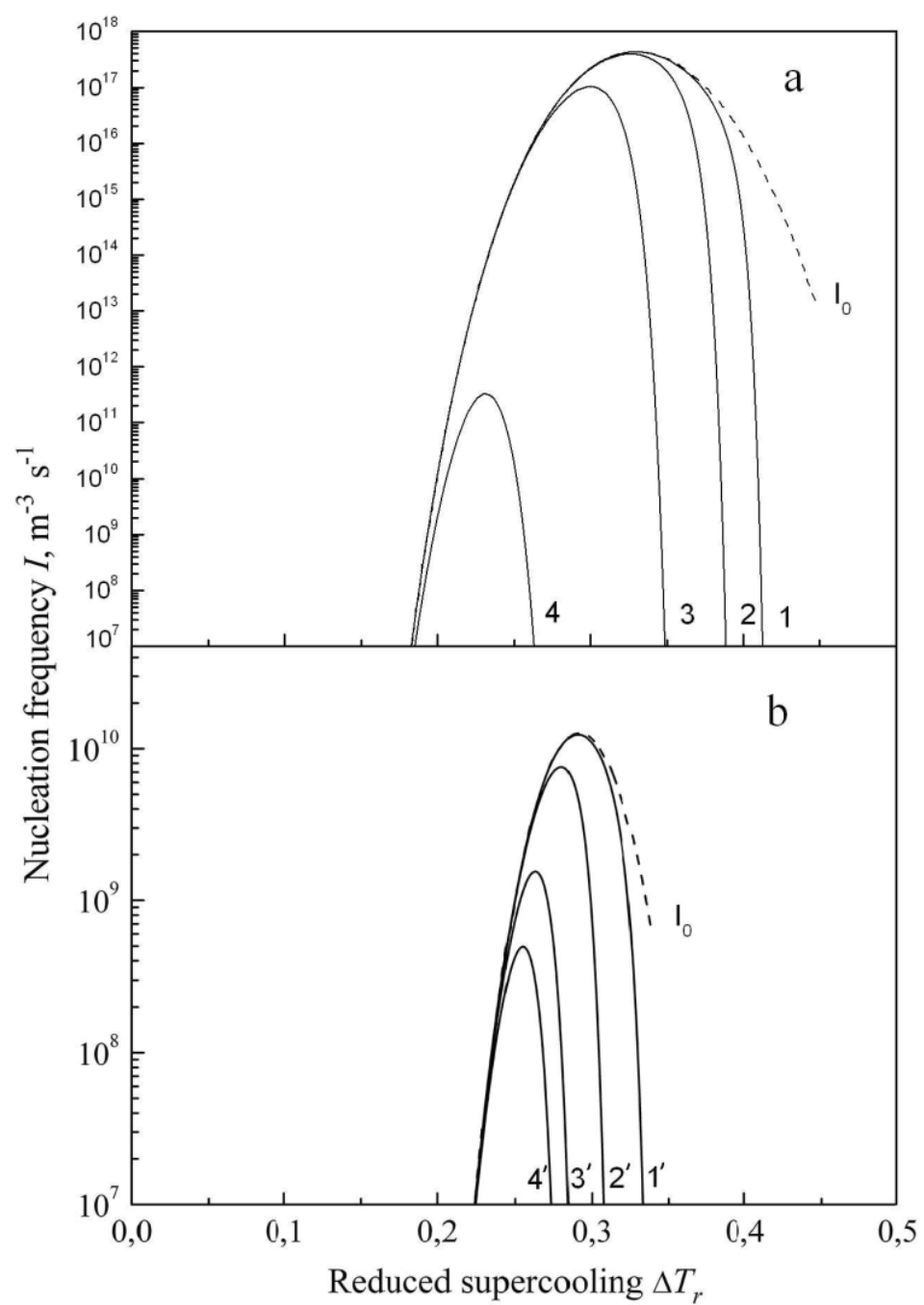

Fig. 5. Dependences of the frequency of stationary $I_{0}$ (dashed line) and nonstationary $I$ (solid lines) nucleation on reduced supercooling $\Delta T_{r}$ for $\mathrm{Mg}_{65} \mathrm{Cu}_{25} \mathrm{Y}_{10}$ (a) и $\mathrm{Zr}_{41.2} \mathrm{Ti}_{13.8} \mathrm{Cu}_{12.5} \mathrm{Ni}_{10} \mathrm{Be}_{22.5}$ (b) alloys quenched from the liquid state with cooling rates $v>v_{\mathrm{C}}(\mathrm{K} / \mathrm{s}): 1-33,6 ; 2-977 ; 3-4,7 \cdot 10^{4} ; 4-1,3 \cdot 10^{7}$ ; 1'-1,3; 2'- 64,4; 3'-9,8 $\cdot 10^{2} ; 4^{\prime}-2,7 \cdot 10^{3}$

As can be seen from the graphs $I\left(\Delta T_{r}\right)$, the maximum values of the stationary nucleation frequency $I_{0}^{\max }$ and the corresponding supercooling of melts $\Delta T_{r}^{\max }$ in alloys based on $\mathrm{Mg}$ and $\mathrm{Zr}$ are differ significantly. For Mg-alloy, these parameters are $\sim 5 \cdot 10^{17}$ $\mathrm{m}^{-3} \cdot \mathrm{s}^{-1}$ and 0.33 , and for an alloy based on $\mathrm{Zr} \sim 1,4 \cdot 10^{10} \mathrm{~m}^{-3} \cdot \mathrm{s}^{-1}$ and 0.29 . Comparing the given values $I_{0}^{\max }$, it can be concluded that one of the reasons providing the advantages of the $\mathrm{Zr}$ alloy with respect to the tendency to noncrystalline solidification is the lower level of the maximum frequency of stationary nucleation. It is also important that the maximum of dependence $I_{0}\left(\Delta T_{r}\right)$ is achieved at a lower value $\Delta T_{r}^{\max }$. This shortens the 
duration of the high-rate nucleation period and further enhances the glass-forming ability of the alloy. However, according to the obtained calculating data, even a combination of relatively low parameter values $I_{0}^{\max }$ and $\Delta T_{r}^{\max }$ does not provide the fixation of a truly amorphous state in the $\mathrm{Zr}_{41,2} \mathrm{Ti}_{13,8} \mathrm{Cu}_{12,5} \mathrm{Ni}_{10} \mathrm{Be}_{22,5}$ alloy under conditions close to equilibrium (at $v \approx 0,1 \mathrm{~K} / \mathrm{s}$ ).

In addition to the value of $I_{0}^{\max }$ and $\Delta T_{r}^{\max }$, another factor that controls the tendency of materials to completely suppress crystallization is the susceptibility of the crystal nucleation kinetics to the dynamic regime of the QLS. This is evidenced by the calculated changes in the dependences $I\left(\Delta T_{r}\right)$ corresponding to different cooling rates. As can be seen from Fig. 5, with increasing $v$, there is a decrease in the maximum values of the nonstationary nucleation frequency and a displacement of the graphs $I\left(\Delta T_{r}\right)$ towards the region of lower supercoolings.

For evidentness and the possibility of a quantitative estimation of the noted transformations of the graphs $I(\Delta T)$, Fig. 6 shows the dependences of the analyzed parameters $I^{\max }$ and $\Delta T_{r}^{\max }$ on the cooling rate of the melts.

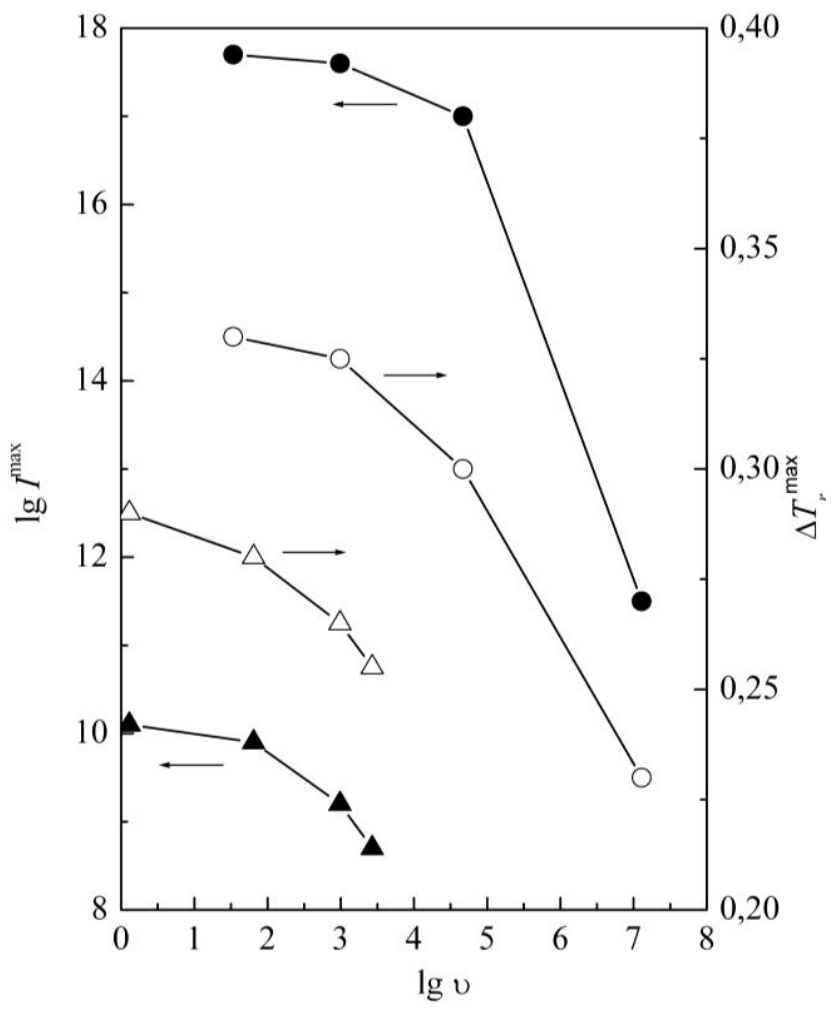

Fig. 6. Dependences of the maximum values of the nonstationary nucleation frequency (dark symbols) and the corresponding reduced supercoolings (light symbols) on the cooling rate for $\mathrm{Mg}_{65} \mathrm{Cu}_{25} \mathrm{Y}_{10}(\bullet, \circ)$ and $\mathrm{Zr}_{41,2} \mathrm{Ti}_{13,8} \mathrm{Cu}_{13,5} \mathrm{Ni}_{10} \mathrm{Be}_{22,5}(\Delta, \Delta)$ alloys

It can be seen that with an increase in the QLS rate, the absolute values of the maxima of the nonstationary nucleation frequency for the Mg-alloy decreases by approximately 6 orders of magnitude, and the corresponding values of the reduced supercooling decreases in the range of $0.33-0.23$. The effect of complete suppression of crystallization is achieved in layers cooled at a rate of $v_{C}^{*}=1,3 \cdot 10^{7} \mathrm{~K} / \mathrm{s}$ at values of 54 
$I^{\max }=3 \cdot 10^{11} \mathrm{~m}^{-3} \cdot \mathrm{s}^{-1}$ and $\Delta T_{r}^{\max }=0,23$. In the layers of the $\mathrm{Zr}$-based alloy, the acceleration of the QLS process is accompanied by a decreasing in the maximum values of $I$ by $\sim 1.5$ orders of magnitude, and the parameter $\Delta T_{r}^{\max }$ from 0.29 to 0.255 . In this case, the numerical values $I^{\max }$ are significantly inferior to those for the Mg-alloy. This increases the glass-forming ability of the $\mathrm{Zr}_{41,2} \mathrm{Ti}_{13,8} \mathrm{Cu}_{12,5} \mathrm{Ni}_{10} \mathrm{Be}_{22,5}$ alloy and provides a real possibility of suppressing the nucleation processes at a cooling rate $v_{C}^{*}=2,7 \cdot 10^{3} \mathrm{~K} / \mathrm{s}$.

\section{Conclusions}

1. Using the algorithm for the coordinated numerical solution of the equations of thermal conductivity and crystallization kinetics for bulk-amorphizing alloys $\mathrm{Mg}_{65} \mathrm{Cu}_{25} \mathrm{Y}_{10}$ and $\mathrm{Zr}_{41,2} \mathrm{Ti}_{13,8} \mathrm{Cu}_{12,5} \mathrm{Ni}_{10} \mathrm{Be}_{22,5}$, the calculated values of the critical thickness $l_{C}$ and cooling rate $v_{C}$ of the melt layers are obtained. At such parameters a conditionally amorphous structure with inclusions of «quenching nuclei», typical for metallic glasses, is formed. Correlation of the results of the computational analysis with the corresponding experimental data has been achieved.

2. Based on the results of the analysis of the dependences of the number of crystallization centers formed in a given volume during the cooling time from $T_{m}$ to $T_{g}$, it is shown that in real conditions of the QLS the criterion of complete suppression of crystallization is fulfilled at the following values of the critical parameters: $l_{C}^{*}=10 \mu \mathrm{m}$, $v_{C}^{*}=2,7 \cdot 10^{3} \mathrm{~K} / \mathrm{s}$ for an alloy based on $\mathrm{Zr} ; l_{C}^{*}=550 \mu \mathrm{m}, v_{C}^{*}=1.3 \cdot 10^{7} \mathrm{~K} / \mathrm{s}$ for Mg-alloy.

3. It has been established that in terms of the degree of influence on the tendency of melts to complete suppression of crystallization, the dominant factor is the tendency to slow down the processes of crystal nucleation with an increase in the cooling rate, which appears itself against the background of relatively low $\left(<10^{18} \mathrm{~m}^{-3} \cdot \mathrm{s}^{-1}\right)$ values of the stationary nucleation frequency.

\section{References}

1. Miroshnichenko, I.S. Zakalka iz zhidkogo sostojanija / I.S. Miroshnichenko. M: Metallurgija, 1982. - $168 \mathrm{~s}$.

2. Miroshnichenko, I.S. K voprosu o prirode amorfnogo sostojanija v metallah / I.S. Miroshnichenko // Izvestija vuzov. Chernaja metallurgija.- 1982. - S. 97 - 103.

3. Busch, R. Thermodynamics and kinetics of the $\mathrm{Mg}_{65} \mathrm{Cu}_{25} \mathrm{Y}_{10}$ bulk metallic glass forming liquid / R. Busch, W. Lin, W.L. Johnson // Appl. Phys. - 1998. - Vol. 83, №8. P. $4134-4141$.

4. Kim, Y.J. Metallic glass formation in highly undercooled $\mathrm{Zr}_{41,2} \mathrm{Ti}_{13,8} \mathrm{Cu}_{12,5} \mathrm{Ni}_{10} \mathrm{Be}_{22,5}$ during containerless electrostatic levitation processing / Y.J. Kim, R. Busch, W.L. Johnson et al.// Appl. Phys. Lett. - 1994. - Vol. 65. - P. 2136 2138.

5. Lysenko, A.B. Kineticheskaja model' massovoj kristallizacii $\mathrm{v}$ priblizhenii jeffektivnyh skorostej zarozhdenija i rosta kristallov / A.B. Lysenko // Visnik Dnipropetrovs'kogo universitetu. Fizika. Radioelektronika. Vyp. 18. - 2011. - T. 19, № 2. - S. $3-11$.

6. Lysenko, A.B. Kinetics of crystallization of the metastable polytype of cerium upon melt quenching /A.B. Lysenko, O.L.Kosinskaya, G.V. Borisova, T.V. Kalinina //Phys. Met. Metallogr. - 2012. - Vol. 113, № 6. - P. 588 - 593. 
7. Lysenko, A.B. Mehanizm i kinetika formirovanija metastabil'noj modifikacii neodima v uslovijah zakalki iz zhidkogo sostojanija / A.B. Lysenko, O.L. Kravets, A.A. Lysenko // Fizika i tehnika vysokih davlenij. - 2009. - T.19, №1. - S.134 - 144.

8. Lysenko, A.B. Modelirovanie processov formirovanija struktury $\mathrm{v}$ uslovijah lazernoj obrabotki s oplavleniem poverhnosti / A.B. Lysenko, N.A. Savinskaja, E.A. Yakunin // Matematicheskoe modelirovanie i informacionnye tehnologii v svarke i rodstvennyh processah. - Kiev: IJeS im. E.O. Patona NAN Ukrainy. - 2010. - s. 97 100.

9. Lysenko, A.B. Vlijanie termicheskogo rezhima zakalki iz zhidkogo sostojanija na mikrostrukturu metallov / A.B. Lysenko, O.L. Kravets, A.A. Lysenko // Metallofiz. Novejshie tehnol. - 2008. - T.30, №3. - S. $415-427$.

10. Lysenko, A.B. Modelirovanie parametrov mikrostruktury bystrozakristallizovannyh metallov / A.B. Lysenko, O.L. Kravec, G.V. Borisova // Fizika i tehnika vysokih davlenij. - 2007. - T.17, №3. - S.52 - 62 .

11. Lysenko, A.B. Kinetika kristallizacii ob\#emno-amorfizirujushhegosja splava $\mathrm{Cu}_{47} \mathrm{Ni}_{8} \mathrm{Ti}_{34} \mathrm{Zr}_{11}$ v uslovijah kokil'nogo lit'ja / A.B. Lysenko, O.L. Kosinskaya, S.V. Gubarev, T.V. Kalinina //Metallofiz. Novejshie tehnol. - 2014. - T. 36, № 10. - S. 1411 -1425 .

12. Gadzyra, N.F. Issledovanie raspredelenija vmorozhennyh centrov kristallizacii po razmeram $v$ amorfnom splave $\mathrm{Fe}_{40} \mathrm{Ni}_{40} \mathrm{~B}_{20}$ / N.F. Gadzyra, E.I. Har'kov, I.A. Yakubtsov // Metallofizika. - 1989. - T.11, №1. - S. 88 - 92.

13. Jianga, J.Z. $\mathrm{IsCu}_{60} \mathrm{Ti}_{10} \mathrm{Zr}_{30}$ abulkglass-forming alloy? / J.Z. Jianga, J. Saida, H. Kato et. al. // Appl. Phys. Lett. - 2003. - Vol. 28, № 23. - P. 4041 - 4043.

14. Skripov, V.P. Spontannaja kristallizatsija pereohlazhdennyh zhidkostej / V.P. Skripov, V.P. Koverda. - M.: Nauka, 1984. - 232 s.

15. Ovsienko, D.E. Zarozhdenie i rost kristallov iz rasplava / D.E. Ovsienko. Kiev: Naukova dumka, 1994. - $254 \mathrm{~s}$.

16. Vreswijk, J. C.A. Nucleation kinetics and critical cooling rate of glass-forming liquids / J.C.A. Vreswijk, R.G. Gossink and J.M. Stevels // J. Non-Cryst. Solids. - 1974. - №16. - P.15 - 26.

17. Waniuk, T.A. Equilibrium viscosity of $\mathrm{Zr}_{41,2} \mathrm{Ti}_{13,8} \mathrm{Cu}_{12,5} \mathrm{Ni}_{10} \mathrm{Be}_{22,5}$ bulk metallic glass-forming liquid and viscous flow during relaxation, phase separation and primary crystallization / T.A. Waniuk, R. Busch, A. Masuhr, W.L. Johnson // Acta Mater. - 1998. - Vol. 46, №15. - P. 5229 - 5236.

18. Mondal, K. On prediction of solid-liquid interfacial energy of glass forming liquids from homogeneous nucleation theory / K. Mondal, B.S. Murty// Mater. Sci. Eng. A. - 2007. - Vol. 454 - 455. - P. $654-661$.

19. Lysenko, A.B. Raschet skorosti ohlazhdenija pri zakalke splavov iz zhidkogo sostojanija / A.B. Lysenko, G.V.Borisova, O.L. Kravets // Fizika i tehnika vysokih davlenij. - 2004. - T.14, № 1. - S.44-53.

20. Lu, Z.P. The correlation between reduced glass transition temperature and glass forming ability of bulk metallic glasses / Z.P. Lu, H. Tan, Y. Li, S.C. Ng // Scripta Mater. - 2000. - Vol. 42. - P. $667-673$.

21. Inoue, A. Stabilization of metallic supercooled liquid and bulk amorphous alloys / A. Inoue // Acta Mater. - 2000. - Vol. 48. - P. 279 - 306. 